\title{
CORRIGENDUM
}

\section{Differential plant damage due to litterfall in palm-dominated forest stands in a Central Pacific atoll - CORRIGENDUM}

\section{Hillary S. Young, Douglas J. McCauley, Amanda Pollock and Rodolfo Dirzo}

DOI: 10.1017/S026646741400008X, Published by Cambridge University Press 22 April 2014.

On page 234 the caption to Figure 1 should have read as follows:

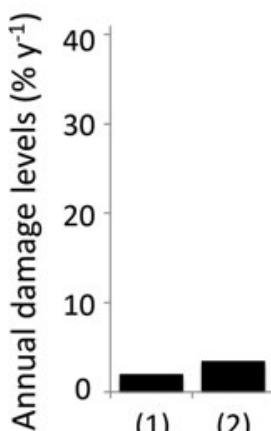

(1) (2)

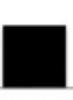

(3)

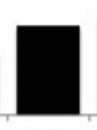

(4)

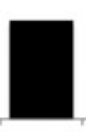

(5)

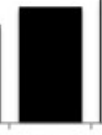

(6)

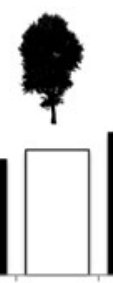

Study System

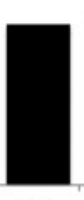

(1)

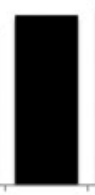

(9)

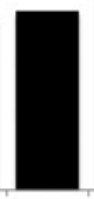

(3)

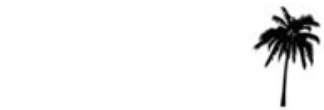

1

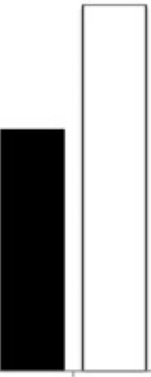

(10) (7)

Figure 1. Annual levels of damage (\% damaged individuals $y^{-1}$ ) to artificial seedlings reported in other studies (black bars) from a wide variety of temperate and tropical forests are consistent with those observed in the mixed-dicot, native-species-dominated stands in this study (first white bar), and much lower than those observed in high Cocos nucifera-dominated stands (second white bar). We present average values for each type of system studied from (1) New Zealand (Gilman et al. 2002); (2) New Jersey (McCarthy \& Facelli 1990); (3) Hawaii (Drake \& Pratt 2001); (4) Panama (Alvarez-Clare \& Kitajima 2009), (5) Brazil (Portela \& Santos (2009), (6) Mack (1998), (7) Line Islands (Young et al. this study), (8) Marquez et al. (2010), (9) Costa Rica (Clark \& Clark1989), (10) Central Amazonia (Scariot 2000).

\section{REFERENCE}

YOUNG, H. S., MCCAULEY, D. J., POLLOCK, A. \& DIRZO, R. 2014. Differential plant damage due to litterfall in palm-dominated forest stands in a Central Pacific atoll. Journal of Tropical Ecology 30:231-236. 